\title{
Óleo essencial e teores de nutrientes da priprioca em resposta à adubação orgânica e à calagem
}

Jessivaldo Rodrigues Galvão ${ }^{1}$

Tiago Kesajiro Moraes Yakuwa²

Júlio Cesar Gomes Costa ${ }^{3}$

Deivison Rodrigues da Silva ${ }^{4}$

Karine Costa de Almeida 5

Leonardo Brandão Araújo ${ }^{6}$

\section{Resumo}

A flora aromática nativa da Amazônia vem sendo alvo de vários estudos básicos. Uma dessas espécies é a Cyperus articulatus L., conhecida como priprioca, cujo óleo essencial tem grande potencial de exploração devido a sua importância na farmacopeia local. O objetivo do trabalho foi avaliar a produção de óleo essencial e os teores de macronutrientes de plantas de priprioca (Cyperus articulatus L.), em resposta à adubação orgânica e à correção do solo. 0 delineamento experimental foi inteiramente casualizado, em esquema fatorial $4 \times 2$ distribuídos em quatro repetições. A cama de aviário foi mais eficiente que a torta de mamona e o esterco de gado promoveu as maiores produções de óleo essencial quando aplicadas às dosagens com $330 \mathrm{~g} \mathrm{vaso}^{-1}$ e $440 \mathrm{~g}$ vaso-1 em solo que recebeu calcário. A cama aviária e a calagem em interação ou com os outros tratamentos foram as mais eficientes no estímulo à absorção dos macronutrientes; a calagem não influenciou a absorção de $\mathrm{K}$, $\mathrm{Ca}, \mathrm{Mg}$ e S quando em interação com a torta de mamona ou com o esterco de gado.

Palavras-chave: Cyperus articulatus. Planta medicinal. Planta aromática. Nutrição mineral. Fertilidade do solo.

\section{Introdução}

As plantas medicinais à medida que deixarem de ser exploradas de forma apenas extrativista deverão garantir maior sustentabilidade à agricultura, especialmente se for criada uma cadeia produtiva englobando a produção, a industrialização e a comercialização. Como a grande maioria das culturas, essas plantas devem responder positivamente a um adequado programa de produção, envolvendo o manejo correto do solo e das espécies nele cultivadas. Portanto, um adequado suprimento de nutrientes, baseando-se em análises químicas do solo e de tecidos das plantas, associado a outras práticas culturais, poderá promover resultados como boa produtividade, lucratividade e proteção ambiental (AMARAL et al., 2010).

1 Universidade Federal Rural da Amazônia, Instituto de Ciências Agrárias. jessigalvao50@gmail.com. Avenida Tancredo Neves 2501, Bairro Montese, Belém, Pará CEP: 66077-580

2 Universidade Federal Rural da Amazônia, PGAGRO. tiago.yakuwa@outlook.com.

3 Universidade Federal Rural da Amazônia, PGAGRO. julio.costa@ufra.edu.br

4 Universidade Federal Rural da Amazônia, PGAGRO. deivisonrodrigues01@live.com.

5 Universidade Federal Rural da Amazônia, PGAGRO. karinecosta_12@hotmail.com.

6 Engenheiro Agrônomo. leonardob029@gmail.com 
Os óleos essenciais são usados para conferir aroma e odores especiais a diversos produtos alimentícios e de perfumaria. Também é de grande relevância o seu uso em medicamentos analgésicos, antissépticos, sedativos, expectorantes, estimulantes, estomáquicos e até mesmo atividade antifúngica e antibacteriana (SILVA, 2011; ALMEIDA et al., 2011). São produtos voláteis e geralmente apresentam uma constituição complexa. Em alguns casos, chegam a conter mais de uma centena de componentes distribuídos em quantidades variáveis (CASTRO et al., 2010).

O mercado internacional de óleos essenciais movimenta anualmente cerca de 1,8 bilhão de dólares, no entanto, a participação brasileira neste cenário ainda é pequena, de apenas 0,1 \% (BIASI et al., 2009). No Estado do Pará, a priprioca Cyperus articulatus L. vem despertando grande interesse científico e econômico devido ao agradável aroma do óleo essencial obtido dos seus rizomas.

Um grande desafio que envolve o uso de plantas medicinais e aromáticas é a obtenção de produtividades estáveis em quantidade e qualidade desejadas, aumentando a confiabilidade da fitoterapia, uma vez que é imensamente variável a produção de princípios ativos nas regiões do país, justificando a importância dos estudos relacionados ao cultivo destas plantas.

Pouco se conhece sobre a nutrição mineral da priprioca, haja vista que muitas das espécies medicinais e aromáticas ainda são consideradas semisilvestres e consequentemente não passaram por manipulação genética, logo faz-se necessário entender melhor o mecanismo de absorção e metabolização dos elementos minerais de forma eficiente (SILVA, 2005).

O objetivo do trabalho foi avaliar a produção de óleo essencial e os teores de macronutrientes de plantas de priprioca (Cyperus articulatus L.) em resposta à adubação orgânica e à correção do solo.

\section{Material e métodos}

O experimento foi realizado no período de janeiro a outubro de 2011 , em condições de casa de vegetação coberta com plástico de 150 microns localizada na Universidade Federal Rural da Amazônia em Belém/Pará. Foram utilizadas amostras de um solo classificado como Latossolo amarelo distrófico (EMBRAPA, 2006), coletado na camada de 0 - 0,20 m de profundidade, em propriedade rural localizada no município de Santo Antônio do Tauá/Pará. O delineamento experimental utilizado foi inteiramente casualizado em esquema fatorial $4 \times 2$, distribuídos em quatro repetições. Os fatores foram quatro adubações orgânicas: torta de mamona, esterco bovino, cama aviária e solo como tratamento controle; dois níveis de correção, com e sem a adição de calcário. As doses do esterco de bovino (0, 280, 420 e 520 g vaso-1 $^{-1}$ e da cama aviária $\left(0,220\right.$, 330 e 440 g vaso-1 $^{-1}$ foram diferenciadas para manter o mesmo conteúdo de $\mathrm{N}$ existente nas doses aplicadas com mamona (0, 100, 150 e 200 g vaso-1 $^{-1}$, baseado na recomendação para a cultura da pimenteira-do-reino na região (CRAVO et al., 2007), que serão comparadas em 0, 1, 2 e 3 doses. A composição química dos substratos orgânicos utilizados no experimento se encontra na Tabela 1. 
Tabela 1. Caracterização química da torta de mamona (TM), esterco bovino (EB) e cama aviária (CA), utilizados como fertilizantes no experimento.

\begin{tabular}{|c|c|c|c|c|c|c|c|c|}
\hline \multirow[t]{2}{*}{ Fontes orgânicas } & $\mathbf{N}$ & $\mathrm{P}_{2} \mathrm{O}_{5}$ & $\mathrm{~K}_{2} \mathrm{O}$ & S & \multirow{2}{*}{$\begin{array}{c}\mathrm{Ca} \\
\mathrm{cmol}_{\mathrm{c}} \mathrm{dm}^{-3}\end{array}$} & \multirow{2}{*}{$\begin{array}{c}\text { MO } \\
\text { Total } \\
\text { g Kg-1 }^{-1}\end{array}$} & \multirow{2}{*}{$\begin{array}{c}\mathrm{C} / \mathrm{N} \\
-\end{array}$} & \multirow{2}{*}{$\begin{array}{c}\mathrm{pH} \\
-\end{array}$} \\
\hline & $(\%)$ & \multicolumn{3}{|c|}{----------mg.dm³-------- } & & & & \\
\hline TM & 5,18 & 1,26 & 1,1 & 0,37 & 0,028 & 74,07 & 7,94 & 5,81 \\
\hline EB & 1,85 & 1,16 & 0,65 & 0,2 & 0,026 & 73,16 & 21,97 & 5,16 \\
\hline $\mathrm{CA}$ & 2,35 & 1,93 & 2,45 & 0,05 & 0,026 & 73,65 & 17,41 & 5,37 \\
\hline
\end{tabular}

Fonte: Elaborada pelos autores (2015).

A calagem foi realizada utilizando uma mistura de $\mathrm{CaCO}_{3}$ e $\mathrm{MgCO}_{3}$ (87 \% de PRNT), na relação $3: 1$, na base de $2,5 \mathrm{t} \mathrm{ha}^{-1}$. 0 solo coletado foi levado ao laboratório, onde foram feitas as análises químicas (TABELA 2).

Tabela 2. Caracterização Química das Amostras de solo utilizadas no experimento (profundidade $0-20 \mathrm{~cm}$ ).

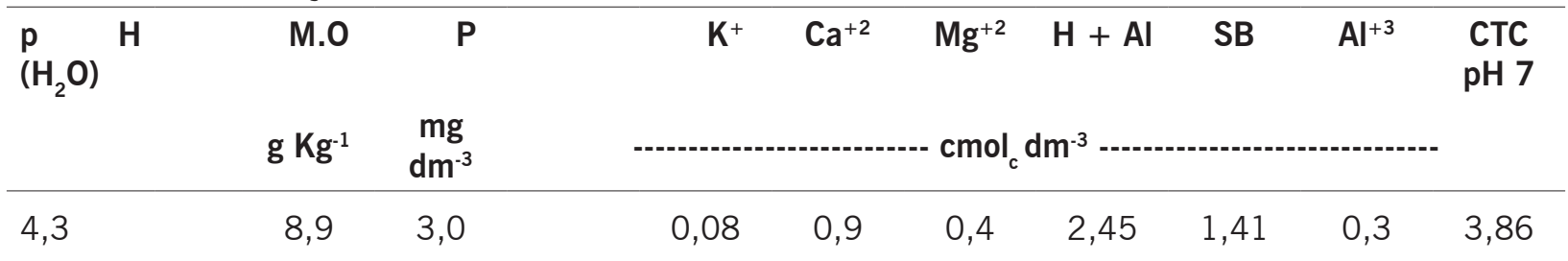

Fonte: Elaborada pelos autores (2015).

Foram determinados pH em água; fósforo disponível (P) usando o extrator Mehlich 1; Cálcio, Magnésio e Alumínio trocáveis extraídos com solução de $\mathrm{KCl} 1 \mathrm{~mol} \mathrm{~L}^{-1}$; Potássio trocável extraído com Mehlich1 e quantificado por fotometria de chama; $\mathrm{H}+\mathrm{Al}$ foram extraídos com solução de acetato de Cálcio 0,5 mol L-1 tamponada a pH 7,0 e determinados por titulometria de neutralização, conforme a Empresa Brasileira de Pesquisa Agropecuária - EMBRAPA (1997).

O solo foi inicialmente incubado por um período de trinta dias. Os vasos preenchidos com solo foram inicialmente saturados com água destilada e drenado por aproximadamente duas horas até a obtenção da capacidade de campo, para então ser incorporados às fontes orgânicas de acordo com os tratamentos estabelecidos, posteriormente, plantou-se um tubérculo de priprioca por vaso.

A coleta dos dados foi feita oito meses após o plantio. As plantas foram coletadas e separadas em tubérculos, raízes e lavadas para retirada do excesso de substrato contido. Em seguida, as raízes foram acondicionadas em sacos de papel e secas em estufa de circulação forçada de ar à temperatura de $60{ }^{\circ} \mathrm{C}$. Na sequência, foram determinados os teores de nutrientes no tecido vegetal. $\mathrm{O}$ teor de $\mathrm{N}$ total foi determinado de acordo com o método micro Kjeldahl e o extrato obtido por digestão nitro-perclória do material vegetal. O P foi determinado por colorimetria, o K, Ca e Mg por espectrofotometria de absorção atômica seguindo a metodologia de Embrapa (2005).

Para a extração do óleo essencial dos rizomas das plantas de priprioca foi aplicado o método de hidrodestilação de arraste por vapor, utilizando o aparelho Clevenger adaptado a um balão volumétrico com capacidade para $1.000 \mathrm{~mL}$. Em cada extração, com a duração de aproximadamente quatro horas, as amostras de $50 \mathrm{~g}$ de rizoma foram colocadas em balão com $500 \mathrm{~mL}$ de água destilada. Após alguns minutos de repouso no hidrolato obtido (mistura de água + óleo), a solução foi filtrada e a quantidade de óleo essencial no recipiente mensurada. 
Os resultados obtidos foram submetidos à análise de variância comparando os tratamentos pelo Teste $\mathrm{F}(\mathrm{P}<0,05)$ e aplicado o Teste Tukey a $5 \%$ de probabilidade, utilizando o programa estatístico Sisvar (FERREIRA, 2011).

\section{Resultados e discussão}

A produção de óleo essencial da priprioca e os teores de nutrientes foram influenciados significativamente pelos tratamentos e suas interações, com exceção ao $\mathrm{P}$ que não sofreu alteração com a aplicação dos tratamentos (TABELA 3).

Tabela 3. Resumo da análise de variância dos tratamentos aplicados: Adubação orgânica (AO) e Correção do solo (COR), para as variáveis produção de óleo (PO) e teores de nutrientes ( $N, P, K, C a, M g)$ no tecido vegetal da priprioca (Cyperus articulatus L.).

\begin{tabular}{lccccccc}
\hline \multicolumn{1}{c}{ Fonte de variação } & $\mathbf{G L}$ & $\mathbf{P O}$ & $\mathbf{N}$ & $\mathbf{P}$ & $\mathbf{K}$ & $\mathbf{C a}$ & $\mathbf{M g}$ \\
\hline $\mathrm{AO}$ & 2 & $* *$ & $* *$ & $\mathrm{~ns}$ & $* *$ & $* *$ & $* *$ \\
$\mathrm{COR}$ & 1 & $* *$ & $* *$ & $\mathrm{~ns}$ & $* *$ & $* *$ & $* *$ \\
$\mathrm{AO}$ COR & 2 & $* *$ & $* *$ & $\mathrm{~ns}$ & $* *$ & $* *$ & $* *$ \\
Resíduo & 75 & 0,002 & 0,58 & 0,26 & 0,62 & 0,52 & 0,53 \\
\hline $\mathrm{CV}$ & & 17,94 & 12,79 & 10,17 & 15,55 & 7,49 & 13,36 \\
\hline
\end{tabular}

Fonte: Elaborada pelos autores (2015).

As maiores produções de óleo essencial foram verificadas com a aplicação de cama aviária em todas as doses de adubação orgânica aplicadas. Houve de forma geral uma elevação da produção de óleo de priprioca à medida que as doses das fontes orgânicas aumentaram, com exceção da torta de mamona que proporcionou redução a partir da terceira dose aplicada (TABELA 4).

A adubação orgânica, além de fonte de nutrientes para as plantas, é capaz de suprir adequadamente as necessidades da cultura e contribuir para a melhoria das qualidades físicas, químicas e biológicas do solo. As plantas medicinais e aromáticas como qualquer outra cultura dependem de suprimento adequado de nutrientes para boas produtividades agrícolas. O fertilizante orgânico meIhora as condições edáficas do solo e pode contribuir positivamente para a produção de biomassa e princípios ativos dependendo da espécie, como observamos no experimento.

Observa-se que ocorreu aumento na produção de óleo à medida que foram aplicadas as doses maiores de esterco bovino.

Sales et al. (2009), ao avaliarem o rendimento de óleo essencial de hortelã-do-campo (Hyptis marrubioides EPL.) sob adubação orgânica com esterco de bovino, destacam um ajuste linear, em que para cada kg de adubo orgânico implementado houve um incremento de 0,0034 g planta-1. Santos (2009), ao estudar altura, rendimento de folha, teor e rendimento de óleo essencial de erva-cidreira-verdadeira (Melissa officinalis L.) sob adubação com esterco bovino, observou que com a aplicação de $15 \mathrm{t} \mathrm{ha}^{-1}$ por ano induziu o aumento do rendimento total de biomassa em 10,7 \% e o rendimento total de óleo essencial em 10,3\% em relação ao tratamento controle. No experimento, foi verificado um incremento de 37,5 \% quando da aplicação da maior dose (520 g vaso ${ }^{-1}$ ) em relação ao controle (dose 0).

No entanto, Assis et al. (2009) indicaram que o esterco bovino influenciou negativamente o teor de óleo essencial de Alecrim-Pimenta. Contrário a esses resultados, Valadares et al. (2010) veri- 
ficaram aumento significativo na produção de óleo essencial de Lippia citriodora (Lam.) com a adição da calagem e esterco bovino. Porém, em uma segunda coleta de material, ocorreu pequena redução.

Brant et al. (2010) verificaram menores teores de óleo essencial em cidrão [Aloysia triphylla ( L' Hérit)] com a utilização de esterco bovino como tratamento. No entanto, nesse estudo, ressalta-se a participação desse esterco no aumento da produção da priprioca.

Assim como no esterco bovino, a aplicação da cama aviária promoveu elevação na produção de óleo essencial de priprioca com o aumento das dosagens.

Tabela 4. Produção de óleo de priprioca (Cyperus articulatus L.) nas doses de adubação orgânica.

\begin{tabular}{lcccc}
\hline Fontes Orgânicas & \multicolumn{4}{c}{ DOSES DE ADUBAÇÃO ORGÂNICA } \\
\hline & 0 & 1 & 2 & 3 \\
TM & $0,08 \mathrm{Cab}$ & $0,29 \mathrm{Ab}$ & $0,15 \mathrm{BCc}$ & $0,11 \mathrm{BCc}$ \\
EB & $0,03 \mathrm{Cc}$ & $0,17 \mathrm{BCc}$ & $0,43 \mathrm{Ab}$ & $0,46 \mathrm{Ab}$ \\
$\mathrm{CA}$ & $0,09 \mathrm{Ca}$ & $0,46 \mathrm{Ba}$ & $0,50 \mathrm{ABa}$ & $0,53 \mathrm{ABa}$ \\
\hline
\end{tabular}

Médias seguidas das mesmas letras, maiúsculas na horizontal e minúsculas na vertical, não diferem entre si em nível de $5 \%$ pelo Teste de Tukey. Torta de mamona (TM), esterco bovino (EB), cama aviária (CA).

Fonte: Elaborada pelos autores (2015).

A correção da acidez do solo por meio da calagem elevou a produção de óleo essencial nos tratamentos com torta de mamona e cama aviária. 0 esterco bovino causou redução na produção de óleo (TABELA 5). Sob efeito da calagem, a cama aviária proporcionou aumento de 25,71 \% na produção de óleo essencial de priprioca que inicialmente era de 0,35 g planta-1 passando para 0,44 g planta $^{-1}$. Com a aplicação de torta de mamona, o acréscimo foi mais significativo, proporcionando um aumento de 120 \% na produção de óleo, ou seja, de 0,10 g planta-1 para 0,22 g planta-1. Inversamente às demais aplicações de adubação orgânica, o esterco bovino promoveu uma redução de 34,78 \% na produção de óleo essencial de priprioca, de 0,31 g planta-1 para 0,23 g planta $^{-1}$.

Tabela 5. Produção de óleo essencial de priprioca (Cyperus articulatus L.) em função da adubação orgânica e da calagem.

\begin{tabular}{ccc}
\hline MO & Sem calcário & Com calcário \\
\hline TM & $0,10 \mathrm{Bb}$ & $0,22 \mathrm{Ab}$ \\
EB & $0,31 \mathrm{Ab}$ & $0,23 \mathrm{Bb}$ \\
CA & $0,35 \mathrm{Ba}$ & $0,44 \mathrm{Aa}$ \\
\hline
\end{tabular}

Médias seguidas das mesmas letras, maiúsculas na horizontal e minúsculas na vertical, não diferem entre si em nível de 5 \% pelo Teste de Tukey. Torta de mamona (TM), esterco bovino (EB), cama aviaria (CA).

Fonte: Elaborada pelos autores (2015).

Por meio das médias encontradas, com boa significância na aplicação da calagem, não pode-se atribuir à cultura uma grande tolerância a solos ácidos. Sales et al. (2009), estudando o hortelã-do-campo (Hyptis marrubioides EPL), demonstraram que não houve interação das doses de adubo orgânico com a presença ou ausência de calagem. No entanto, Corrêa et al. (2010) observaram que 
as doses de adubação mineral e orgânica (avícola) influenciaram significativamente o crescimento das plantas, rendimento e composição química do óleo essencial de orégano.

Oliveira Júnior (2005), ao avaliar o efeito das aplicações de calcário e adubação mineral e orgânica (esterco de curral) sobre a concentração e o rendimento do óleo essencial de arnica (Lychonophora ericoides), observou que as variáveis estudadas foram influenciadas pela interação entre calagem e adubação. $\mathrm{O}$ autor ainda ressalta que os tratamentos de adubação mineral e mista com calagem e mineral sem calagem foram os que apresentaram os menores teores de óleo essencial. Além disso, complementa que o tratamento orgânico sem calagem apresentou menor rendimento de óleo essencial, ao passo que os maiores rendimentos foram obtidos com os tratamentos mineral e misto sem calagem.

Nas plantas que receberam o tratamento com torta de mamona, a calagem não mostrou resultados significativos entre eles.

O esterco bovino e a cama aviária sofreram influência da calagem e a correção do solo proporcionou a maior absorção de $\mathrm{N}$ pelas plantas. Os teores de $\mathrm{P}$ não foram afetados pela correção do solo. Os teores de $\mathrm{K}$ foram afetados significativamente pela correção do solo apenas na aplicação da cama aviária em que a calagem proporcionou maiores teores deste elemento. Os teores Ca, semeIhantes aos de K, foram maiores com a cama aviária após a correção do solo. Os teores de Mg, com a calagem, apresentaram valores menores nas adubações orgânicas realizadas, com exceção à cama aviária. Com relação aos teores de $\mathrm{S}$, a calagem também proporcionou maiores valores com a cama aviária (TABELA 6).

Avaliando o efeito do teor de $\mathrm{N}$ nas raízes, não foi verificada interação entre o uso da calagem e a adição da torta de mamona. No entanto, o uso de cama aviária e esterco bovino com a adição de calcário apresentou os maiores teores de N. A prática do manejo do solo com adubação orgânica produz diversos benefícios quando utilizada de forma correta. Nesse aspecto, a contribuição da adubação orgânica torna-se uma ferramenta fundamental, tendo em vista benefícios como suprimento de nitrogênio ao sistema, aumento no teor de matéria orgânica e de outros elementos.

Amaral (2010), ao avaliar a concentração de nutrientes na parte aérea de Baccharis trimera, destaca a fonte cama de aviário, pois mais de 60 \% das quantidades de nitrogênio e fósforo existentes também se encontram na forma mineral e, portanto, não precisam ser decompostos pelos microrganismos para se tornarem disponíveis às plantas.

Na maioria dos adubos orgânicos, o N é o nutriente mais abundante, apresentando-se como constituinte de moléculas orgânicas que, com o processo de mineralização, liberam esses nutrientes em forma de minerais assimiláveis pelas plantas. Smith e Hadley (1989) relatam que parte do N, presente em adubos orgânicos resiste à rápida mineralização e torna-se disponível somente às culturas subsequentes e que o uso de compostos não só supre as plantas com quantidade considerável de nutrientes, mas contribui para manter a fertilidade natural, o que envolve os ciclos biológicos dos nutrientes nos solos cultivados. 
Tabela 6. Teores de N, P, K, Ca, Mg e S em raízes de priprioca (Cyperus articulatus L.) em função das adubações orgânicas e da calagem.

\begin{tabular}{|c|c|c|c|c|c|c|c|c|c|c|}
\hline \multirow[b]{3}{*}{ MO } & \multirow{2}{*}{\multicolumn{2}{|c|}{$\begin{array}{c}N \\
(\%)\end{array}$}} & \multirow{2}{*}{\multicolumn{2}{|c|}{$\frac{P}{g^{-3}{ }^{-3}}$}} & \multicolumn{2}{|c|}{ K } & \multicolumn{2}{|c|}{$\mathrm{Ca}$} & \multicolumn{2}{|c|}{ Mg } \\
\hline & & & & & - -..--..-.. & -.--.--.--... & $\cdots \mathrm{cmol}_{\mathrm{c}} \mathrm{d}$ & $n^{-3}-\cdots$ & -.......... & -.-.---.-. \\
\hline & $\mathrm{CC}$ & SC & $\mathrm{CC}$ & SC & $\mathrm{CC}$ & SC & $\mathrm{CC}$ & SC & $\mathrm{CC}$ & SC \\
\hline TM & $5,59 \mathrm{Ab}$ & 5,98 Aa & $1,55 \mathrm{Aa}$ & $1,52 \mathrm{Aa}$ & 4,43 Ba & $5,22 \mathrm{Ab}$ & 3,20 Aab & 3,06 Aa & $1,69 \mathrm{Bb}$ & $2,08 \mathrm{Aa}$ \\
\hline EB & $5,70 \mathrm{Ab}$ & $5,10 \mathrm{Bb}$ & 1,65 Аa & 1,63 Аa & 4,48 Ba & 7,28 Aa & 3,03 Bb & $\begin{array}{c}3,22 \\
\text { Aab }\end{array}$ & $1,28 \mathrm{Bc}$ & 2,24 Aa \\
\hline$C A$ & 7,52 Aa & 5,93 Ba & 1,56 Аа & $1,54 \mathrm{Aa}$ & 5,09 Аа & $3,99 \mathrm{Bc}$ & 3,25 Aab & 2,56 Bb & 1,99 Aa & $1,06 \mathrm{Bb}$ \\
\hline
\end{tabular}

Médias seguidas das mesmas letras, maiúsculas na horizontal e minúsculas na vertical, não diferem entre si em nível de $5 \%$ pelo Teste de Tukey. Torta de mamona (TM), esterco bovino (EB), cama aviária (CA), com calagem (CC), sem calagem (SC).

Fonte: Elaborada pelos autores (2015).

Os teores de fósforo não foram influenciados pela calagem nas diferentes adubações orgânicas estudadas. A aplicação de resíduos orgânicos reduz a fixação de fósforo no solo e aumenta a eficiência de utilização dos fertilizantes fosfatados aplicados, e os resíduos orgânicos, ao interagirem com o solo, podem ter efeitos similares ao do calcário (carbonatos de cálcio e de magnésio) pela precipitação de ferro e alumínio (HUE, 1990). Andrade, Fernandes e Faquin (2003), trabalhando em solos de várzea, verificaram que a aplicação de resíduo orgânico, calcário e gesso reduz a fixação de fósforo.

Os maiores teores de $\mathrm{K}$ encontrados na matéria seca da priprioca foram observados com a ausência da calagem, com a aplicação da torta de mamona e esterco bovino. Com a cama aviária, o efeito da calagem foi significativo, promovendo grande aumento nos teores de K. Essa falta de resposta de calcário na torta de mamona e esterco bovino pode ser explicada, em parte, pelo curto período de reação, uma vez que a aplicação deu-se 30 dias antes do plantio. Por outro lado, apesar de o solo se apresentar com acidez elevada, o teor de Al trocável era baixo, não constituindo, portanto, impedimento para o desenvolvimento das raízes. Os valores significativos verificados com a cama aviária podem estar relacionados à alta concentração de macronutrientes em sua composição (ZHANG et al., 1998), proporcionando aumento no carbono total, no teor de matéria orgânica (SINGH et al., 2009) e consequentemente aumento do $\mathrm{pH}$ do solo.

Não foram observados efeitos significativos nos teores de Ca, com a aplicação do calcário em relação à torta de mamona. Com a adição do calcário no esterco bovino ocorreu uma redução nos teores de Ca no tecido vegetal da priprioca. A adição do calcário na cama aviária provocou elevação nos teores de $\mathrm{Ca}$, com efeitos altamente significativos.

Janegitz et al. (2011), em trabalho realizado com diferentes adubações orgânicas, com e sem a aplicação de calcário, observaram que o esterco bovino apresentou melhores resultados que a torta de mamona. Nos tratamentos sem calcário a torta de mamona foi superior, por ter apresentado uma rápida decomposição, levando em consideração a sua eficiência de acordo com a quantidade de adubo utilizado. Esses resultados se assemelham aos da pesquisa, evidenciando a importância da torta de mamona como fertilizante orgânico, mesmo sem a calagem.

Os teores de Mg no tecido vegetal da priprioca foram reduzidos com a calagem na aplicação da torta de mamona e esterco bovino. Na cama aviária observam-se acréscimos nos teores desse nutriente com a calagem. 0 excesso de cálcio em relação ao magnésio na solução do solo pode prejudicar a absorção do magnésio, assim como o excesso de magnésio pode prejudicar a absorção de 
cálcio, semelhante ao que ocorre para o potássio (MALAVOLTA et al., 1997). Amaral et al. (1999), ao avaliarem a omissão de macronutrientes em manjericão (Ocimum sp.), destacaram um aumento acentuado na concentração de Ca nas raízes no tratamento em que houve omissão de Mg, fato este, evidenciado provavelmente pelo antagonismo entre esses elementos.

\title{
Conclusão
}

A maior produção de óleo essencial da priprioca ocorre com a aplicação da cama aviária em solo com a adição de calcário.

No tecido vegetal de priprioca o teor de $\mathrm{N}$ é maior com a aplicação da cama de aviário e com a adição de calcário.

Os nutrientes $\mathrm{P}$, Ca e Mg apresentaram os maiores teores quando da adição de esterco bovino sem a calagem.

\section{Priprioca essential oil and nutritional content in response to organic fertilization and liming}

\begin{abstract}
The native aromatic flora of Amazon has been the subject of several basic studies. One of these species is Cyperus articulatus L., known as priprioca, whose essential oil has great potential for exploitation due to its importance in the local pharmacopoeia. The objective of this work was to evaluate the production of essential oil and macronutrient contents of priprioca plants in response to organic fertilization and soil correction. The experimental design was completely randomized, in a $4 \times 2$ factorial scheme distributed in four replications. Poultry litter was more efficient than castor bean cake and cattle manure, promoting the highest yields of essential oil when applied to dosages with $330 \mathrm{~g} \mathrm{pot}^{-1}$ and $440 \mathrm{~g} \mathrm{pot}^{-1}$ in soil where limestone was applied. Poultry litter and liming, in interaction, or with the other treatments, were the most efficient in stimulating the absorption of macronutrients; liming did not influence the uptake of $\mathrm{K}, \mathrm{Ca}, \mathrm{Mg}$ and $\mathrm{S}$ when in interaction with castor bean or cattle manure.
\end{abstract}

Keywords: Cyperus articulatus. Medicinal plant. Aromatic plant. Mineral nutrition. Soil fertility.

\section{Referências}

ALMEIDA, L. F. D.; CAVALCANTI, I. W.; VIANA, W. P.; LIMA, E. O. Screening da Atividade Antifúngica de Óleos Essenciais sobre Candida Albicans. Revista Brasileira de Ciências da Saúde, João Pessoa, v. 14, n. 4, p. 51-56, 2011. Disponível em: http://periodicos.ufpb.br/index.php/rbcs/article/viewFile/9818/5686. Acesso em: 28 set. 2015.

AMARAL, A. S.; RADÜNZ, L. L.; MOSSI, A. J.; SANTI, A.; ROSA, N. M. F. F.; FEITEN, F. Rendimento de matéria seca e de óleo essencial de Baccharis trimera com adubação química e orgânica. Revista de Ciências Agroveterinárias, Lages, v. 9, n. 1, p. 20-28, 2010. Disponível em: http://revistas.bvs-vet.org.br/rca/article/download/35145/39516. Acesso em: 30 set. 2015. 
AMARAL, J. F. T. do; FOnSECA, A. F. A da; MARTINEZ, H. E. P.; PEREIRA, P. R.; FOnTES, P. C. R. Deficiências de macronutrientes Fe e B em manjericão (Ocimum sp.), em cultivo hidropônico. Revista Ceres, Viçosa (MG, Brasil), 1999. Disponível em: http://www.ceres.ufv.br/ojs/index.php/ceres/ article/view/2540/533. Acesso em: 28 set. 2015.

ANDRADE, A. T.; FERNANDES, L. A.; FAQUIN, V. Organic residue, limestone, gypsum, and phosphorus adsorption by lowland soils. Scientia Agrícola, Piracicaba, v. 59, n. 2, p. 349355, abr/jun., 2003. Disponível em: http://www.scielo.br/scielo.php?script=sci_arttext\&pid=S0103-90162002000200022. Acesso em: 30 set. 2015.

ASSIS, B. F. S.; MARTINS, E. R.; SOUZA, M. F.; MELO, M. T. P.; CARVALHO JUNIOR, W. G. O. Produção de Fitomassa e de Óleo Essencial de Alecrim-Pimenta em Função da Adubação Orgânica. Revista Brasileira de Agroecologia, v. 4, n. 2, 2009. Disponível em: http://aba-agroecologia.org.br/revistas/ index.php/rbagroecologia/article/view/9625. Acesso em: 16 set. 2015.

BIASI, L. A. Plantas aromáticas do cultivo à produção de óleo essencial. Curitiba, PR: Layer Studio Gráfico e Editora Ltda., 2009.

BRANT, R. S.; PINTO, J. E. B. P.; BERTOlUCCI, S. K. V.; AlBUqUERQUE, C. J. B. Produção de Biomassa e teor de óleo essencial de cidrão em função da adubação orgânica. Revista Horticultura Brasileira, v. 28, n. 1, 2010. Disponível em: http://www.scielo.br/scielo.php?script=sci_abstract\&pi$d=S 010205362010000100021 \&$ Ing=en\&nrm=iso\&tlng=pt . Acesso em: 11 set. 2015.

CASTRO, H. G.; PERINI, V. B. M.; SANTOS, G. R.; LEAL, T. C. A. B. Avaliação do teor e composição do óleo essencial de Cymbopogon nardus (L.) em diferentes épocas de colheita. Revista Ciência Agronômica, Fortaleza, v. 41, n. 2, p. 308-314, 2010. Disponível em: http://ccarevista.ufc.br/seer/ index.php/ccarevista/article/view/287. Acesso em: 10 set. 2015.

CORRÊA, R. M.; PINTO, J. E. B. P.; REIS, E. S.; COSTA, L. C. B.; ALVES, P. B.; NICULAN, E. S.; BRANT, R. S. Adubação orgânica na produção de biomassa de plantas, teor e qualidade de óleo essencial de orégano (Origanum vulgare L.) em cultivo protegido. Revista Brasileira de Plantas Medicinais, Botucatu, v. 12, n. 1, p. 80-89, 2010. Disponível em: http://www.scielo.br/scielo.php?pi$\mathrm{d}=$ S1516-05722010000100012\&script=sci_abstract\&tlng=pt. Acesso em: 10 set. 2015.

CRAVO, M. S.; VIÉGAS, I. J. M.; BRASIL, E. C. Recomendação de Adubação e Calagem para o Estado do Pará. Belém: EMBRAPA, 2007.

FERREIRA, D. F. Sisvar: a computer statistical analysis system. Ciência e Agrotecnologia, Lavras, v. 35, n. 6 , p. 1039-1042, 2011.

HUE, N. V. Interaction of $\mathrm{Ca}\left(\mathrm{H}_{2} \mathrm{PO}_{4}\right)_{2}$ applied to an Oxisol and previous sludge amendment: soil and crop response. Communications Soil Science Plant Analysis, New York, n. 1-2, v. 20, p. 61-73, 1990. Disponível em: http://www.tandfonline.com/doi/abs/10.1080/00103629009368215?journalCode $=$ Icss20. Acesso em: 14 out. 2015.

JANEGITZ, B. C.; FIGUEIREDO-FILHO, L. C. S.; MARCOLINO-JUNIOR, L. H.; SOUZA, S. P. N.; PEREIRA-FILHO, E. R.; FATIBELLO-FILHO, O. Development of a carbon nanotubes paste electrode modified with crosslinked chitosan for cadmium(II) and mercury(II) determination. Journal of Elec- 
troanalytical Chemistry, v. 660, n. 1, p. 209-216, 2011. Disponível em: http://www.bv.fapesp.br/ pt/publicacao/26575/development-of-a-carbon-nanotubes-paste-electrode-modified-w/. Acesso em: 30 out. 2015.

MALAVOLTA, E.; VITTI, G. C.; OLIVEIRA, S. A. Avaliação do estado nutricional das plantas: princípios e aplicações. 2. ed. Rev. atual. Piracicaba: POTAFOS, 1997.

OLIVEIRA JÚNIOR, A.; FAQUIN, V.; PINTO, J. E. B. P.; LIMA SOBRINHO, R. R.; BERTOLUCCI, S. K. V. Teor e rendimento de óleo essencial no peso fresco da arnica, em função da calagem e adubação. Horticultura Brasileira, v. 23, n. 3, jul./set. 2005. Disponível em: http://www.scielo.br/pdf/hb/ v23n3/a09v23n3. Acesso em: 14 out. 2015.

ROSINI, F.; DONATI, G. L.; NASCENTES, C. C.; ARRUDA, M. A. Z.; NOGUEIRA, A. R. A.; NÓBREGA, J. A. Espectrometria de absorção atômica com forno tubular na chama e aerossol térmico (TS_FF_ AAS): comportamento dos elementos selênio e cobalto. São Carlos (SP, Brasil): Embrapa, 2005.

SALES, J. F.; PINTO, J. E. B. P.; BOTREL, P. P.; SILVA, F. G.; CORREA, R. M. Acúmulo de Massa, teor foliar de nutrientes e rendimento de óleo essencial de hortelã do campo (Hyptis marrubiodes EPL.) cultivados sob adubação orgânica. Bioscience Journal, Uberlândia, v. 25, n. 1, p. 60-68, 2009. Disponível em: http://www.seer.ufu.br/index.php/biosciencejournal/article/view/6785. Acesso em: 05 out. 2015.

SANTOS, M. F.; MENDONÇA, M. C.; CARVALHO FILHO, J. L. S.; DANTAS, I. B.; SILVA, M, R.; BLANK, A. F. Esterco bovino e biofertilizante no cultivo de erva-cidreira-verdadeira (Melissa officinalis L.). Revista Brasileira de Plantas Medicinais, Botucatu, v. 11, n. 4, p. 355-359, 2009. Disponível em: http://www.scielo.br/scielo.php?script=sci_arttext\&pid=S1516-05722009000400001. Acesso em: 05 out. 2015.

SILVA, A. B. Estudo Integrado da Priprioca (Cyperus sp.) no Estado do Pará. 2005. 65 f. Dissertação (Mestrado) -Universidade Federal Rural da Amazônia, Belém, 2005.

SILVA, S. M. Sistemas e épocas de cultivo na produção agronômica e de óleo essencial de Melissa officinalis L. 2011. 48 f. Dissertação (Mestrado)- Universidade Federal de Uberlândia, Uberlândia, 2011.

SINGH, Y.; GUPTA, R. K.; THIND, H. S. Poultrylitter as a nitrogen and phosphorus source for the ricewheat cropping system. Biology Fertilidad Soils, v. 45, p. 701-710, 2009. Disponível em: https:// link.springer.com/article/10.1007\%2Fs00374-009-0373-z . Acesso em: 05 out. 2015.

SMITH, S. R.; HADLEY, P. A. Comparison of organic and inorganic nitrogen fertilizers their nitrate-N and ammonium- $\mathrm{N}$ release characteristics and effects on the growth response of lettuce (Lactuca sativa L. cv. Fortune). Plant and soil, v. 115, n. 1, p. 135-144, 1989. Disponível em: https://link. springer.com/article/10.1007/BF02220704. Acesso em: 05 out. 2015.

VALADARES, R. V.; SOUZA M. F.; VALADARES S. V.; DUARTE R. F.; FERNANDES L. A.; MARTINS E. R. Calagem e adubação orgânica na produção de biomassa e óleo essencial em Lippia citriodora (Lam.). Horticultura Brasileira, v. 28, p. 3591-3597. 2010. Disponível em: http://www.abhorticultura.com.br/eventosx/trabalhos/ev_4/a2527_t4576_comp.pdf. Acesso em: 05 out. 2015. 
ZHANG, H. Animal Manure Can Raise Soil pH. Production technology, Department of Plant and Soil Sciences, v. 10. n. 7, 1998. Disponível em: http://animalwaste.okstate.edu/welcome-folder/ pt98-7manureraisessoilph.pdf. Acesso em: 05 out. 2015.

\section{Histórico editorial}

Submetido em: 05/10/2017

Aceito em: 08/02/2018 